\title{
MULTIFUNCTIONAL FUSELAGE DEMONSTRATOR: THERMOPLASTIC COMPOSITE SKIN MANUFACTURING DEVELOPMENTS
}

\section{EMUS 2020}

\author{
W.M. VAN DEN BRINK ${ }^{(1)}$, W.J. VANKAN(1), J. DE KRUIJK ${ }^{(1)}$, S.L. VELDMAN ${ }^{(2)}$, R. \\ HERRMANN $^{(3)}$ \\ (1) Royal Netherlands Aerospace Centre (NLR), Anthony Fokkerweg 2, Amsterdam, The Netherlands, \\ Wouter.van.den.Brink@nlr.nl, Jos.Vankan@nlr.nl \\ ${ }^{(2)}$ GKN-Fokker, Industrieweg 4, Papendrecht, The Netherlands, Bas.Veldman@fokker.com, \\ ${ }^{(3)}$ Airbus Operations GmbH, Airbus allee 1, Bremen, Germany, Ralf.Herrmann@airbus.com
}

Key words: Computational Methods, Modular assembly, Innovative Manufacturing, Virtual Manufacturing Structure,

\begin{abstract}
Within Clean Sky 2 the design and manufacturing of the fuselage of new single aisle aircraft is investigated through a large, multi-functional fuselage demonstrator, see Figure 1. The main objectives of this demonstrator are to enable high production rates with a minimum of 60 aircraft per month and to reduce structural weight and recurring cost. The envisaged demonstrator shall validate high potential multi-functional combinations of airframe structures, systems, cargo and cabin technology concepts for the next generation fuselage and cabin, using advanced materials and innovative design principles.

One of the key innovations for the multi-functional fuselage demonstrator is the modular assembly of pre-equipped sub-assemblies, see reference [1] and [4]. To make a step in the design and manufacturing of such integrated multi-disciplinary fuselage sub-assemblies, including components of structures, systems, cabin and cargo, advanced materials and manufacturing methods are required. Thermoplastic composites and their highly automated fibre placement production techniques and advanced joining methods, offer the flexibility and efficiency that is needed for the production of much more pre-equipped sub-assemblies to enable the modular assembly process for the future aircraft production supply chain.
\end{abstract}




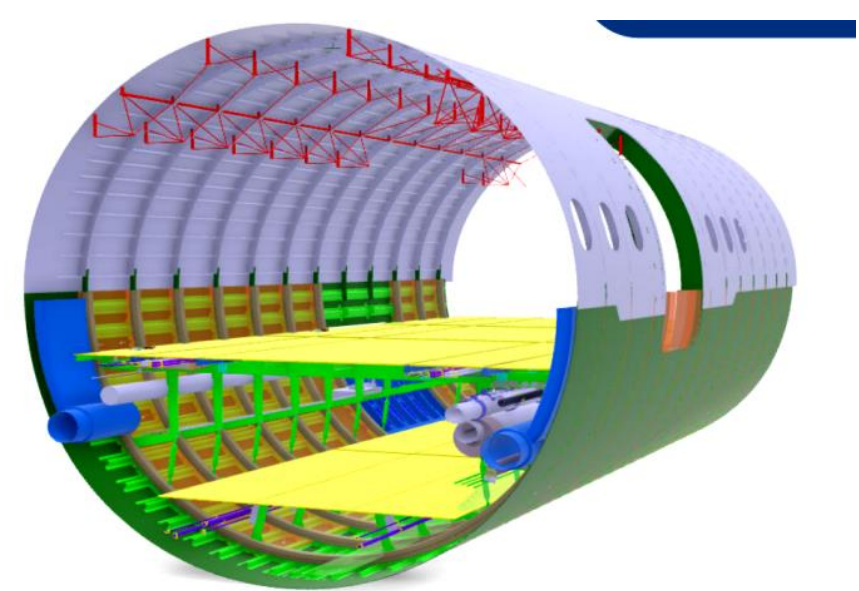

Figure 1: CAD model of the full fuselage.

This paper presents investigations on the development of several innovative manufacturing methods for the full-scale single aisle skin component for the lower fuselage. Because of the complexity of the considered multi-functional structures, the risk for manufacturing of the demonstrator and the level of detail that is required for the high level of manufacturing accuracy, detailed 3D modelling and analyses are necessary for predictions of the manufacturing processes. The results presented in the paper will include the modelling steps for manufacturing of the thermoplastic skin part from the la
(composite modeller) to automated fibre placement manufact
dynamic handling of the thin skin section and dreping prom
simulations). The modelling results support the specification
processes, which are currently further developed.
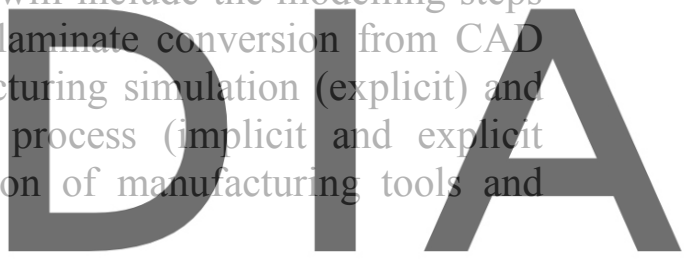

\section{Register for freeptobteps/ldyww.scipedia.com to download the version without the watermark}

To deliver a double-digit fuel burn reduction for the Large Passenger Aircraft (LPA) segment next generation fuselage structure concepts are needed in which cabin, cargo and physical system elements are integrated. The three main overarching objectives for future fully equipped Single Aisle Aircraft fuselages compared to the state of the art are:

- Enable a High Rate Production (HRP) of minimum 60 shipsets per month

- Reduce a total fuselage weight by $10 \%$

- Reduce the recurring cost by $20 \%$

For this purpose a full scale fuselage section will be developed, manufactured and delivered as manufacturing demonstrator. The lower half of this section is $180^{\circ}$ full scale multifunctional integrated thermoplastic fuselage shell, incl. cabin and cargo floor structure and relevant main interior and system elements. Advanced design principles, innovative system architecture, advanced materials and processes to generate high potential solutions for next generation fuselages will be used. One of these advanced design principles enabling the multifunctional structures is the use of virtual process technologies. 
During the last five years the virtual process simulations using physical behaviour has received increased attention. The benefit of virtual process simulations are to gain insight in the behaviour and influence of process parameters, before the actual manufacturing, , thus reducing the risk by mitigating actions. Manufacturing experience, trials, and small size demonstrators can therefore be assisted by powerful simulation tools. A nice overview of virtual processing tools is shown in references [2], [3] and [5].

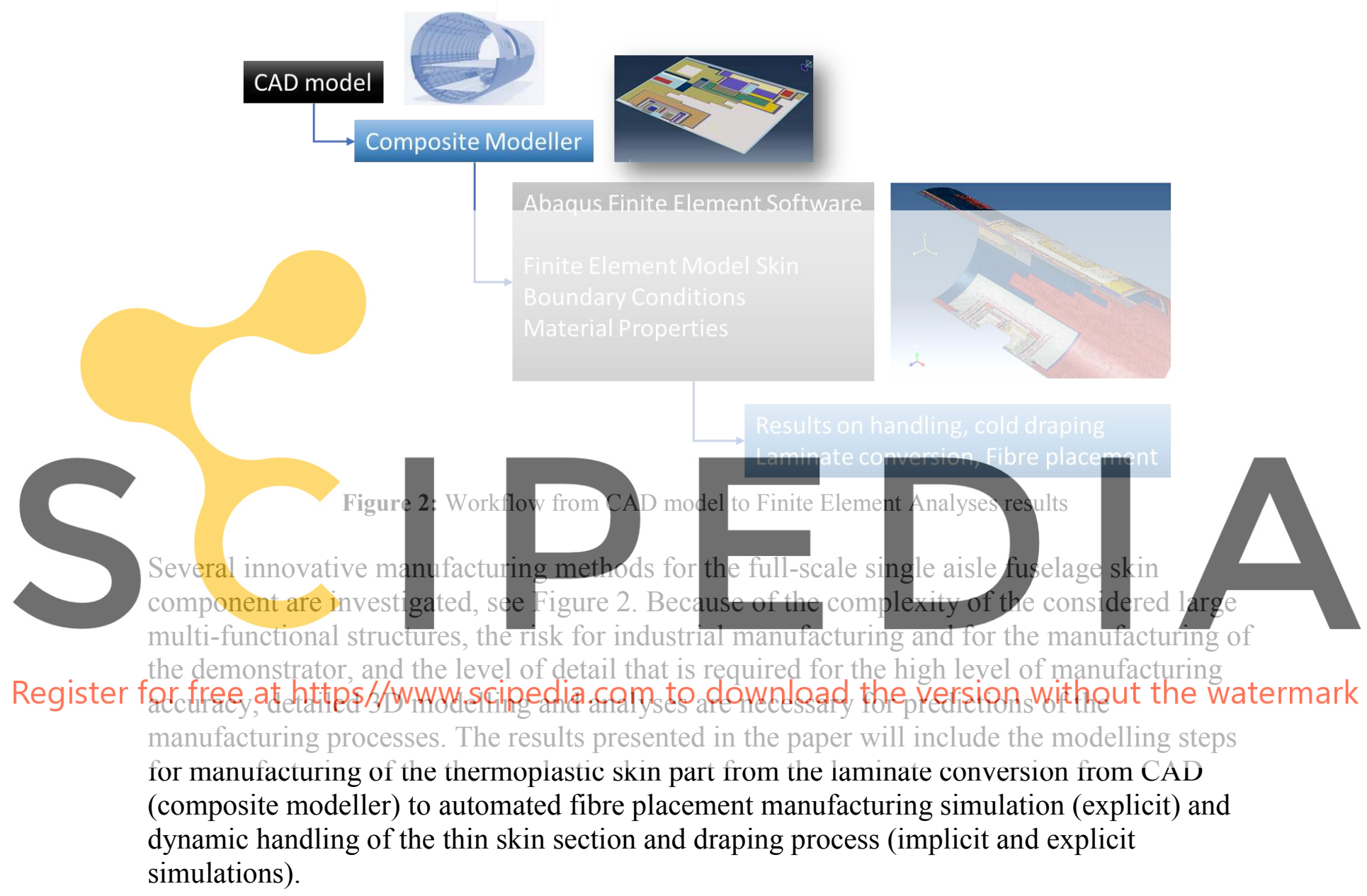

\section{METHODS AND MODELS}

In this section of the paper the methods used to enable multifunctional structures will be presented. The topics are composite modeller, handling simulation and draping and fibre placement simulations.

\subsection{Composite modeller}

The composite skin consists of many layers and ply drops that are defined in the CAD files (Catia). Correct transfer of geometrical and composite data into the finite element software can be very challenging. Furthermore the detailed translation from the curved fuselage skin 
defined in CAD to the flat skin model needed for the manufacturing simulation introduces additional challenges. Therefore the fibre orientation of the layer and normal directions of the laminate need to be accounted for. To perform this translation the composite modeller is used which has the beforementioned mapping with high accuracy. Composites Modeler for Abaqus/CAE extends the ply modelling features in Abaqus by providing fibre simulation capabilities.

\subsection{Fibre placement simulation}

The composite layer deposition is performed using a fibre placement machine, also known as advanced fibre placement AFP. To gain insight in the behaviour and dynamics of this production process a simulation using dynamic explicit is performed on the fibre placement. This approach allows for assessing the influence of tackiness to the mould, bending and cutting using material damage parameters of the composite fibres/tows. The virtual fibre placement head can deposit 8 composite tows simultaneously. In contrast to most AFP simulations this included the physical effects.
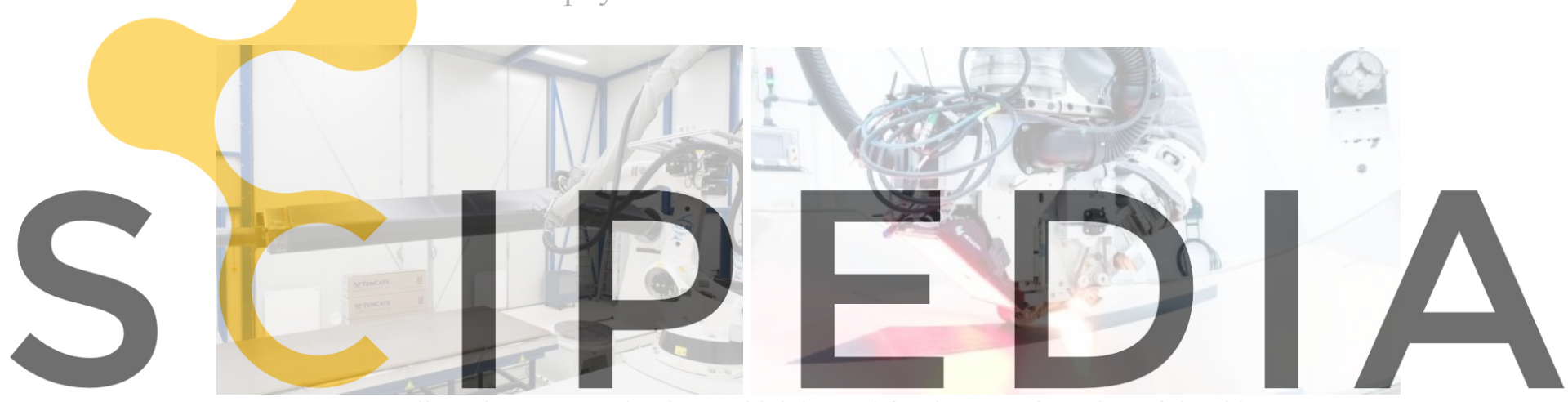

Figure 3: Fibre placement technology which is used for the manufacturing of the skin. $[6,7$

Register for free at https//www.scipedia.com to download the version without the watermark 2.3 Handling simulation an Draping simulation

The manufacturing process foreseen for the large skin section includes the handling and draping of several sub-laminates into the consolidation mould. To gain insight in the dynamic behaviour of these quite large and thin and flexible skin sub-laminate structures, dynamic explicit simulations are performed. The skin is picked up using suction cups and then carefully placed into the curved mould.

(2)

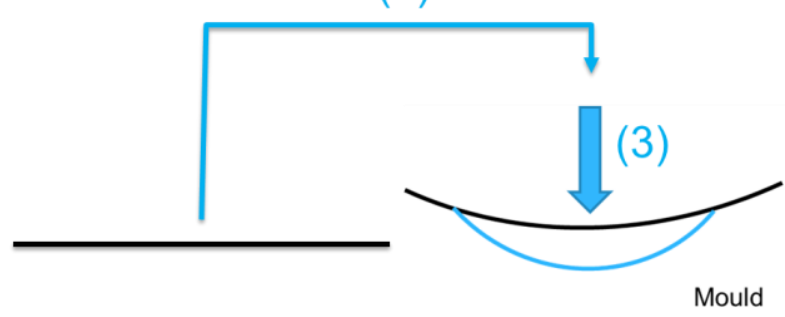

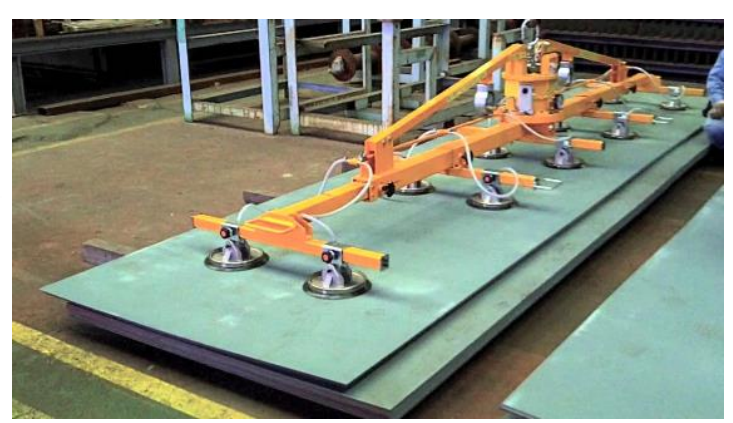

Figure 4: Schematic of the skin after fibre placement to the mould involving a shape transition from flat to curved and on the right an image of a vacuum lifting device [8] 
The method used for modelling enables variation of laminate thickness, number of suction cups and their distribution over the skin. The main aim of these simulations is to analyse in detail behaviour of these large and thin laminates during the transition to avoid that the skin gets damaged during this transport to the mould. The requirements are set on maximum suction cup load is $200 \mathrm{~N}$ and interlaminar shear stress (ILSS) due to bending of the preform laminate of $6 \mathrm{MPa}$.

\section{RESULTS}

In this section the results for the several topics related to the manufacturing of the multifunctional fuselage demonstrator skin is discussed.

\subsection{Composite modeller}

As described in section 2.1 the composite modeller is used for creating the skin finite element model. The ply book design of the skin for the demonstrator contains over 120 detailed ply definitions. These definitions are active in different regions over the skin in order to create a balanced and as-designed skin. To do this manually would be to big an effort so therefore the composite modeller is used. This uses the CAD Catia file and Abaqus finite element mesh as
input to map the laminate to the mesh. Tho designs were made, a coarse design with 50.000
elements and one with 500.000 elements (S4R shells). For the second design also the mesh
was more structured to enable correet mapping of the ramp zone details ysing eldments with
average size of 10 mn.

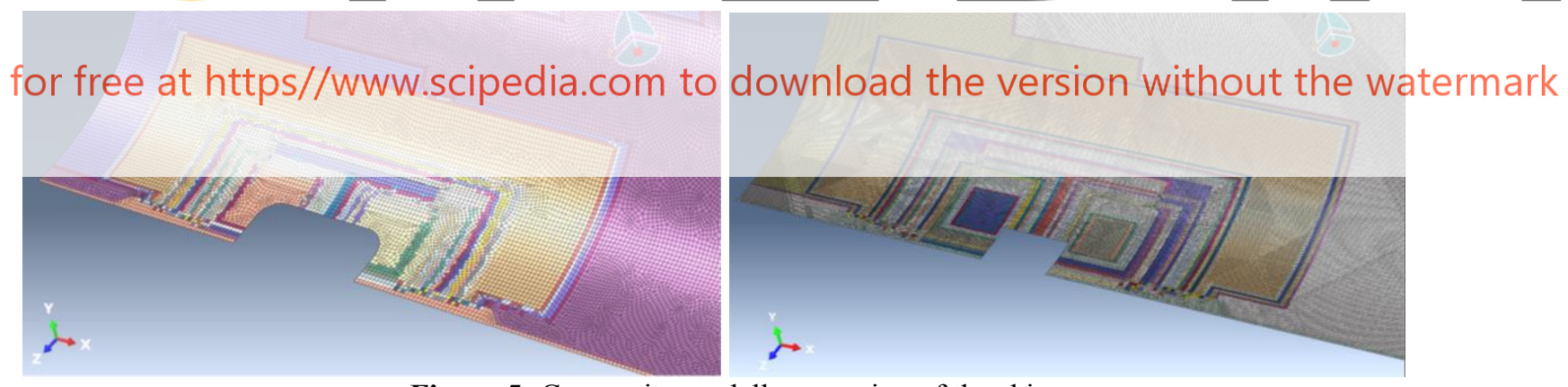

Figure 5: Composite modeller mapping of the skin

The mapping of the laminate from CAD to the finite element model was performed successfully. The overall computational performance proved to be challenging due to the large amount of ply definitions and sections. The result of the mapped finite element skin model was used for the handling and draping simulations described in section 3.3.

\subsection{Fibre placement simulation}

As described in section 2.2 the fibre placement simulation is used. For the manufacturing of the skin the fibre placement manufacturing is used. In order to gain understanding of the 
process a simulation was created using Abaqus Explicit, so-called virtual FPM. This consists of the following parts, which are shown in see Figure 6: the metal mould (white), the fibre placement head and tow guides (blue), the individual tows ( 8 in total), cutting knives, roller (blue). The mould, cutting knives and fibre placement head are rigid parts. The carbon fibre reinforced plastic tows are elastic and have damage modelling and cohesive interaction (tack) with the mould. The roller is also elastic with rubber properties.
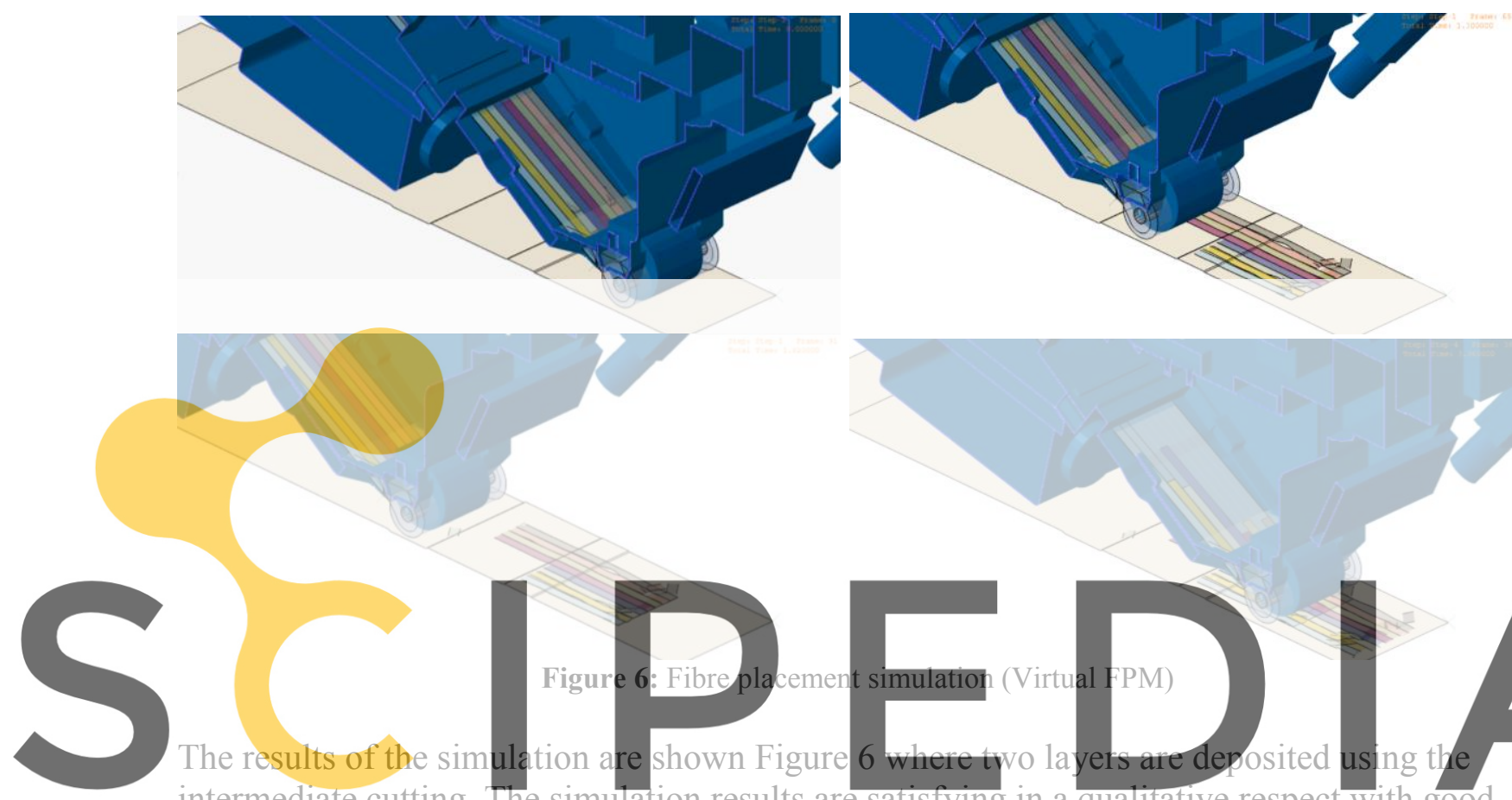

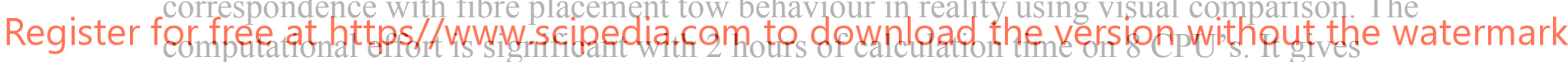 \\ valuable insight in the sensitivities and speed of the process. The approach will be used for the}

skin to investigate chailenging areas. At this point it is not feasibie to have the entire skin part simulated using this approach because of computational limitation. Further work also involves the combination with thermal simulation and laser heating followed by a cooldown distortion simulation and validation using actual measurements.

\subsection{Handling simulation and Draping simulation}

As described in section 2.3 the manufacturing process foreseen for the large lower skin of the demonstrator includes several fibre placed sub-laminates, handling and draping into the consolidation mould, see Figure 7. Several models are created with different suction cup supports. The thinnest -and therefore the most flexible- skin sub-laminate is selected as worst case for the analyses and consists of 6 plies. 

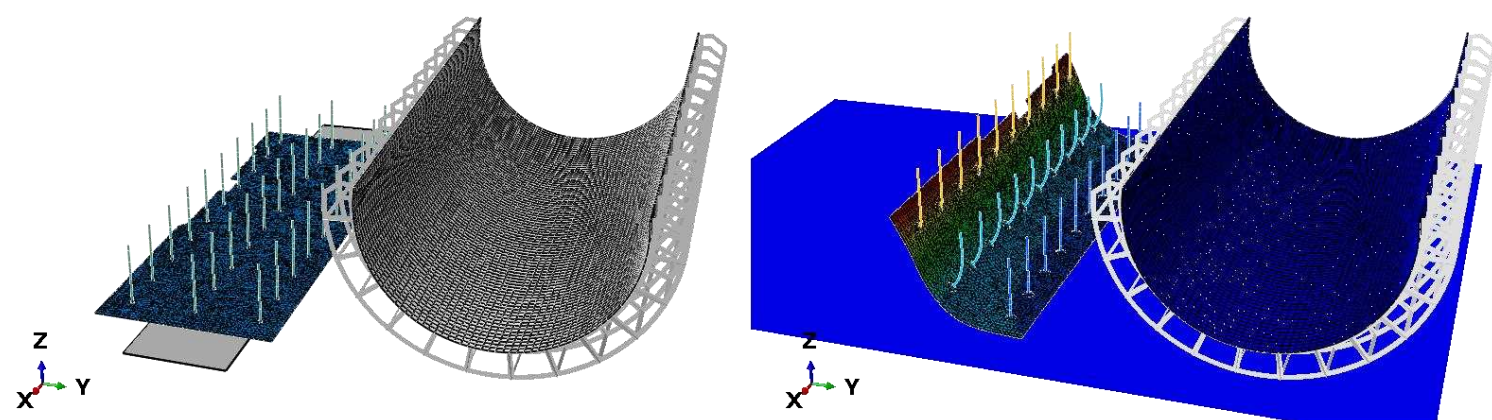

Figure 7: Model and result of the skin transport using suction cups. On the left in blue the flat placed skin and the curved mould. On the right the pick up of the flat skin using suction cups and chains towards the mould.

The dynamic handling and draping finite element simulation gives very good insight in the behaviour of the flexible thermoplastic skin. Too little supporting suction cuns will give considerable bending and interlaminar shear stress, high suction cup loading and possible damage to the unconsolidated thermoplastic skin. A suction cup arrangement of $3 \times 10$ gives satisfactory results and normal and shear loading of the suction cups within the safety limits of $200 \mathrm{~N}$ loading. Also the bending is limited and shows low ILSS values of $1-2.4 \mathrm{MPa}$. This option is chosen for the manufacturing and transport process.

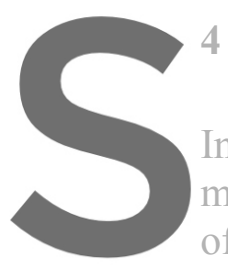

\section{CONCLUSIONS AND RECOMIMENDATIONS}

In this paper the investigations on the developinent of several

methods for the full-scale single aiste fuselage skin componen a of the envisaged multi-functional structures has b benefits

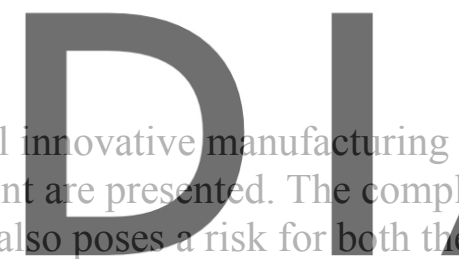
A industrial manufacturing and the manufacturing of the demonstrator and increases the level of

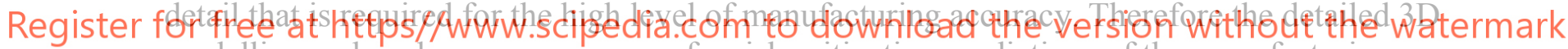
modelling and analyses are necessary for risk-mitigating predictions of the manufacturing processes.

The presented modelling steps for manufacturing of the thermoplastic skin part are the laminate conversion from CAD (composite modeller), the fibre placement manufacturing simulation (explicit), and the dynamic handling of the thin skin section and draping process (implicit and explicit simulations). The simulation results have given valuable insight in the behaviour. This insight is used for improving the manufacturing of multi-functional structures and obtain first time right parts.

\section{ACKNOWLEDGEMENT}

This project has received funding from the Clean Sky 2 Joint Undertaking (JU) under grant agreements Nos 807097 and 945583 . The JU receives support from the European Union's Horizon 2020 research and innovation programme and the Clean Sky 2 JU members other than the Union. 
The work and support of C.P. Groenendijk from NLR is kindly acknowledged.

\section{DISCLAIMER}

The results, opinions, conclusions, etc. presented in this work are those of the author(s) only and do not necessarily represent the position of the JU; the JU is not responsible for any use made of the information contained herein.
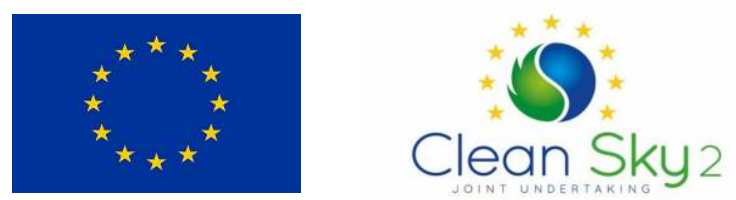

\section{PEFEPENCES}

[1] S.L. Veldman, P.J. Kortbeek, P.C. Wölcken, R. Herrmann, J. Kos, I. Fernandez Villegas, Development of a multifunctional fuselage demonstrator, Proceedings of Aerospace Europe Conference, Bordeaux, France, 25 February 2020 to 28 February 2020

[2] D. Otten, T.A. Weber, J.C. Arent, Manufacturing Process Simulation - On Its Way to Industrial Application, International Journal of Aviation, Aeronautics, and Aerospace

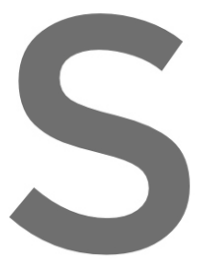
Volume 5 Issue

[3] Dörr, Dominik \& \& Kärger, Luis Codes for Form 106. 10.1016/j.p
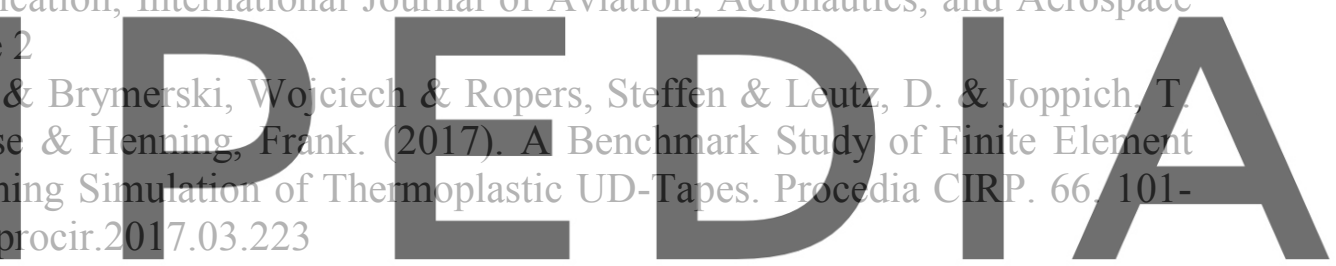

[4] W.M. van den Brink, J. Kos, W.J. Vankan, A.J. de Wit, Large carbon fibre reinforced

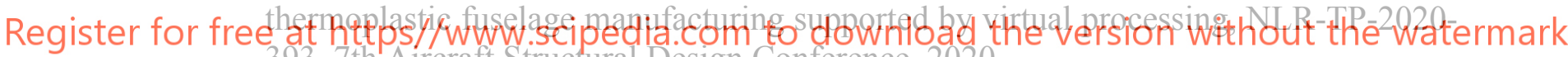
393, 7 th Aircraft Structural Design Conference, 2020

[5] L. Paletti, W.M. van den Brink, Virtual manufacturing for composites, overview and status, Presented at the ISCM 2018, November 2018, Marknesse, Netherlands, NLRTP-2019-367

[6] Website: https://www.compositesworld.com/articles/thermoplastic-compositedemonstrators-eu-roadmap-for-future-airframes-, G. Gardiner, Thermoplastic composite demonstrators - EU roadmap for future airframes

[7] Website: https://www.sucohs-project.eu/news/sucohs-newsletter-no-3, SUCOHS EU project newsletter 3

[8] Website: https://www.vacuumlift.jp/eng/vac/m6075.html, VD M-6075 Fukoku Corp. Japan 